\title{
La producción de consentimiento entre los trabajadores: una pregunta que dura 40 años. Entrevista al sociólogo marxista Michael Burawoy
}

\author{
Paula Varela \\ UBA - Conicet \\ paula.varela.ips@gmail.com
}

Michael Burawoy es conocido en Argentina como el autor de $E l$ consentimiento en la producción, ${ }^{1}$ libro de cabecera para todos los que estudiamos el mal llamado "mundo del trabajo", particularmente lo que sucede en las fábricas. Sin embargo, es bastante más que eso. Nacido en Manchester en una familia judía de origen ruso, Burawoy viene persiguiendo desde hace 40 años la pregunta por la construcción de consentimiento entre los explotados. Con esa pregunta se topó en Zambia en 1968, en pleno proceso poscolonial, cuando hizo un trabajo en la industria del cobre y descubrió las articulaciones entre el régimen fabril y la segregación racial. De alli surgió The Colour of Class on the Copper Mines: From African Advancement to Zambianization (Manchester University Press, 1972). Volvió a imponerse como preocupación cuando, ya devenido sociólogo, se empleó como trabajador de una metalúrgica en las afueras de Chicago en 1974 y realizó la etnografia que es la base de su libro más conocido y el único traducido al castellano: Manufacturing Consent: Changes in the Labor Process in the Monopolist Capitalism (Chicago Press, 1982). Este trabajo es el que le permite consolidar la idea de la imposibilidad de comprender lo que sucede en el espacio productivo sin establecer la relación entre dicho espacio y el contexto político-económico en el que está inscripto, dando origen al concepto de

1. El consentimiento en la producción. Los cambios en el proceso productivo en el capitalismo monopolista, Madrid: Ministerio de Trabajo y Seguridad Social, 1989.

(Archivos, año VII, $\mathrm{n}^{\circ} 13$, septiembre de 2018, pp. 165-177) 
"régimen político de producción" que va a profundizar en The Politics of Production: Factory Regimes Under Capitalism and Socialism (Londres: Verso, 1985) y en The Radiant Past. Ideology and reality in Hungary's road to capitalism (Chicago Press, 1994), a partir de la comparación entre su experiencia como obrero en Chicago y su experiencia fabril en Hungria en los años 80, mientras este país se encontraba bajo la órbita soviética. Y finalmente fue para responder a esta pregunta que, a inicios de los 90, se dedicó a hacer trabajo de campo en una fábrica en Rusia, en momentos en que comenzaba la restauración capitalista. Pero esa misma preocupación fue la que lo llevó a adoptar el marxismo como punto de vista teórico y la etnografía como modo de investigación, desarrollando una serie de discusiones teórico-metodológicas que pueden encontrarse en textos como The Extended Case Method: Four countries, four decades, four great transformations, and one theoretical tradition (University of California Press, 1997), o Sociological Marxism, escrito junto a Eric Olin Wright. ${ }^{2}$ En sintesis, estamos ante una rara avis de la academia norteamericana: un profesor que recorre las aulas reivindicándose abiertamente marxista, un investigador que sostiene una batalla metodológica a muerte contra el inductivismo y un sociólogo que propone volver a pensar la idea del intelectual orgánico relacionando la sociología con los movimientos anticapitalistas.

\section{¿Cogo?
cago \\ ¿Cómo llegaste a trabajar como obrero en Allied Corporation en Chi-}

Lo que pasó, esencialmente, fue que debía volver a Inglaterra después de hacer mi Maestría en la Universidad de Zambia. Pero no fui a Inglaterra sino que fui a Estados Unidos, donde había pasado momentos muy emocionantes en 1967-1968. Puedo dar una explicación racional de por qué Chicago, pero lo cierto es que fue la única universidad que me aceptó. Entonces, aterricé ahí y, por supuesto, nadie estaba realmente interesado en África cuando llegué, porque África no estaba yendo en la dirección esperada y había todo tipo de explicaciones de carácter cultural al respecto, que eran, precisamente, el tipo de teoria a la que yo me oponía mucho. Esto fue en 1972, (André) Gunder Frank ya había escrito sus artículos sobre desarrollo del subdesarrollo ${ }^{3}$ basados en su trabajo en América Latina y había llegado a ser bastante influyente en África, al igual que (Frantz) Fanon, como intentos de comprender el colonialismo a través de una lente marxista. Ese punto de vista era exactamente el contrario al que se hacia en Estados Unidos basado en

2. Incluido en Jonathan Turner, Handbook of Sociological Theory, Nueva York: Springler, 2001.

3. Véase El desarrollo del subdesarrolo, La Habana: Pensamiento Crítico, 1967. 
una suerte de falta de preparación cultural de los africanos para el desarrollo. Así que pensé, "está bien, voy a llevarles el problema a su propia casa". Así que fui y me metí a trabajar en una fábrica. Por supuesto que ya habia estado interesado en la sociologia industrial en Zambia, pero ahora era una pregunta marxista la que me hacia: cómo dar sentido a la experiencia real de los trabajadores en una fábrica capitalista.

$\mathrm{Y}$, por supuesto, era un momento interesante porque había un renacer del marxismo particularmente influenciado por el marxismo francés, el estructuralismo francés. Claro que Chicago no era, obviamente, el corazón del marxismo. Todo lo contrario. Pero había un hombre polaco en el Departamento de Ciencia Política, Adam Przeworski, que acababa de regresar de París y estaba "lleno de marxismo". Alli yo aprendí mi Gramsci de él, una visión particular de Gramsci. Y supongo que eso me llevó a comenzar a pensar "soy un etnógrafo, así es como yo hago mi trabajo y tengo que pensar cómo tomar estas ideas para comprender la naturaleza de la clase trabajadora en los Estados Unidos". Entonces entré a trabajar en la fábrica en 1974. Chicago había tenido una fuerte tradición en etnografia, incluso en etnografia del lugar de trabajo. Pero había muy poca etnografia en ese momento, toda la tradición había sido un tanto abandonada. Además yo era bastante hostil al tipo de etnografia que se hacía en Chicago porque hacian un fetiche de los cercos, de las fronteras. Trataban de delimitar las comunidades de algún modo, para construirlas como una unidad cerrada. En sentido contrario, la Escuela de Manchester, a la que pertenecía el antropólogo con el que yo estudié en Zambia, Jaap van Velsen, ya había problematizado eso en la década del 50 diciendo: "Mirá, vos no podés encerrar una comunidad y mucho menos una fábrica", y preguntándose "¿cómo vamos a estudiar la industria con nuestro método etnográfico?”. Y la respuesta a eso fue el desarrollo del "método del caso extendido" (extended case method), que es lo que posteriormente yo desarrollé, modificándolo. Porque la forma en que lo concebía la Escuela de Manchester era sumamente inductiva, no tenía un punto de vista teórico marxista aunque a menudo sus estudios eran una especie de análisis de clase.

Pero volviendo a cuando llegué a Chicago, me encontré con que aún estaban colgados con esta especie de estudio de comunidades cerradas, de barrios cerrados, donde la categoria de clase no aparecía, excepto, tengo que ser justo, en un único libro, el famoso libro de William Kornblum, Comunidad de cuello azul, ${ }^{4}$ que sí miraba las divisiones étnicas al interior de la clase obrera, en la comunidad de los trabajadores del acero. Pero había muy poco de este tipo de análisis, así que decidí que tenía que tratar de llevar el marxismo a la experiencia de Chicago porque

4. Blue Collar Community, Universidad de Chicago, 1975. 
no había marxistas, a excepción de Przeworski, que pensó que estaba loco, porque tenía una visión macro de la política y le interesaba, básicamente, por qué los socialistas nunca lograron llegar al poder a través de las elecciones y la forma en que la politica electoral desorganizaba a la clase trabajadora. Entonces no podia entender lo que estaba haciendo trabajando en una fábrica. Pero de todos modos, lo hice. Y tomé básicamente a estos marxistas franceses, llevé a Poulantzas, Althusser y Gramsci a la fábrica.

No es muy habitual la mezcla que vos hiciste entre Gramsci y Althusser en tu análisis del régimen fabril...

Bueno, hay muchas conexiones entre ellos. La más obvia es que Althusser ya estaba hablando de aparatos ideológicos de Estado y eso era similar a la idea de Gramsci del Estado no como formación puramente coercitiva sino también como formación ideológica. Y Gramsci estaba muy concentrado, a diferencia de muchos marxistas, en analizar cómo era experiencia viva de los trabajadores y los campesinos, lo que lo llevó a analizar el sentido común y el buen sentido. Althusser hizo algo similar: habló sobre la importancia de la ideología, entendida no como un conjunto de representaciones o ideas, sino como una experiencia viva que, bajo el capitalismo, mistificaba la existencia de la explotación, es decir, el fetichismo de la mercancía como otra forma de experiencia vívida. Esa es una visión muy althusseriana de la ideología. Pero de hecho, creo que en realidad las ideas de los estructuralistas franceses, Poulantzas, Balibar, Althusser, se pueden encontrar en Gramsci, aunque todos lo atacaban por ser un historicista (en referencia a la idea de que existen etapas de desarrollo de la clase obrera). Esto que digo, ahora me parece una obviedad, pero en su momento creo que tuvo que ver con la influencia de Przeworski en mí, porque él también veía esta cercanía entre ambas teorías. Hoy creo que es incluso más cercana de lo que él lo veía. No sé si es un estilo francés, pero sucede que, básicamente, si encontrás a alguien que tiene ideas similares a las tuyas, entonces lo atacás, en lugar de construir sobre ellas, y eso es lo que le sucedió con Gramsci: tomaron sus ideas y luego lo atacaron. Más tarde, Bourdieu hace algo muy similar. Pero en definitiva creo que hay una conexión estrecha entre las ideas de Gramsci sobre el Estado y el marxismo francés de los años 60 y 70 . El tema es que la mayoría de ellos no hace trabajo empírico de tipo etnográfico. Eso fue algo novedoso de mi trabajo. Los que sí habian hecho etnografias dentro de un marco gramsciano fueron los ingleses. Alguien como Paul Willis, cuyos estudios sobre educación tuvo un marco muy similar, está muy influenciado por sus ideas. Stuart Hall, obviamente, es otro muy influenciado por Gramsci. A esos autores no les resultaría en absoluto extraño una etnografia de comunidades 
o lugares de trabajo realizada con marco gramsciano. A los franceses sí. Y a los norteamericanos también pero por motivos distintos: por el amor a la Escuela de Chicago que es tan inductiva y por la idea de que no hay que traer la teoria a la etnografia. El marxismo, por ende, aparece como algo ajeno al trabajo etnográfico aunque en verdad no lo es. Pero es excepcional una etnografia realizada bajo el marco de la teoría marxista. Es interesante porque los sociólogos franceses, en general, ven a la Escuela de Chicago como la escuela de sociología más importante de Estados Unidos, y creo que es, básicamente, por su "teoría fundamentada" (grounded theory), en la que se supone que obtenés la verdad por sumergirte en el mundo. El problema es que esa idea hace que se pierda el contexto más amplio dentro del cual se configura realmente la experiencia viva de ese mundo. Por eso yo me opuse, y me opongo mucho, a ambos presupuestos de la Escuela de Chicago: el antiteoricismo y la idea de que las comunidades son unidades en sí mismas (la idea de comunidades cerradas). Y traté de remediar ambos problemas en la forma en que estudié esa fábrica del sur de Chicago: por un lado, trayendo la teoría al centro del análisis del régimen fabril y tratando de establecer los lazos entre este régimen y el contexto más general del capitalismo. Yo había hecho algo similar cuando estudié en Zambia la reproducción de la segregación racial al interior de las corporaciones de cobre, mirando las formas en que los negros reemplazaban a los blancos en los cargos de dirección fabril, y poniéndolo en el contexto más amplio de la Zambia postcolonial. Pero en esa oportunidad fue menos consciente en términos teóricos. Ahora me había vuelto mucho más autoconsciente de esta cuestión teórica y el marxismo era la teoría que estaba tratando de desarrollar, trayendo estas teorías del Estado al análisis de la fábrica. Y tomando nota de lo que Gramsci había dicho en los Estados Unidos acerca de que la hegemonía nace de la fábrica. Así que esa fue la razón de ser de esa etnografia: llevar la teoría directa y conscientemente al mundo empírico, y ver ese mundo empírico en su contexto más amplio.

¿Y vos creés que esa tesis gramsciana de que la hegemonía nace de la fábrica sigue siendo correcta hoy, en este momento de la clase obrera?

Bueno, no sé si yo pensé que era correcta incluso en ese momento. Quiero decir: ciertamente era correcta para el sector monopólico de la economía en ese momento. Esas instituciones de las que hablé, el Estado Interno y el Mercado de Trabajo Interno, y la forma en que esos juegos eran jugados, era una característica de un sector particular de la economía donde los sindicatos eran fuertes, donde había una especie de arena protegida, donde vos podias, efectivamente, organizar el consentimiento. En el sector más competitivo de la economía, donde 
había empleo mucho más precario, era mucho más dificil organizar el consentimiento y es probable que haya habido formas de organización del trabajo más despóticas. Por ejemplo, en el contexto de África del que hablaba antes, yo escribí sobre el régimen politico en el lugar de trabajo y lo llamé "despotismo colonial". En Chicago yo estaba tratando de ser específico. No estaba diciendo que el consentimiento esté organizado en todas las fábricas en todas partes de la misma manera, sino que de hecho esta era una manera un tanto especifica del capitalismo avanzado. Y, de hecho, pensé que esa forma de régimen fabril duraria mucho más de lo que duró. En realidad, después de que realicé el estudio, comenzó a desaparecer más o menos en 1980. Entonces, creo que sigue siendo importante estudiar cuál es el régimen político en la producción. Pero creo que es dificil mantener la afirmación, al modo en que lo hice a mediados de los 70 , de que la fábrica es un lugar central para la organización del consentimiento. Las condiciones son tan diferentes ahora en los lugares de trabajo que casi se puede decir, como a veces digo, que es un privilegio ser explotado. Hay tan pocos puestos de trabajo asalariado estables en la clase trabajadora que en realidad los trabajadores tienden a ser mucho más inactivos, al menos en ese espacio particular. Si esa inactividad es consentimiento u obediencia, es una buena pregunta de investigación. Esa es la cuestión en la actualidad, ¿no? El aumento de un empleo más precario en áreas cada vez mayores de la economía, incluida la universidad. Entonces, creo que con esta idea de que la hegemonía nace de la fábrica, Gramsci hablaba del fordismo. En realidad, no sé de qué estaba hablando, pero lo dijo, así que mi papel fue descubrir qué significaba y creo que con esa idea capturó algo fundamental de la era fordista, capturó algo significativo respecto de los Estados Unidos, porque Gramsci siempre ha sido históricamente específico. Y lo que capturó respecto de los Estados Unidos fue que la ausencia del llamado feudalismo marcó una gran diferencia en cuanto a dónde tienen lugar el consentimiento y dónde tiene lugar la lucha de clases.

Hiciste mención a la relación entre teoría y trabajo empírico, que es una relación siempre tortuosa para el sociólogo que realiza estudios de caso y más aún para el etnógrafo. ¿Podrías decir de qué modo se articulan especificamente en tu trabajo?

Pasé mucho tiempo en los últimos 40 años en este departamento (de Sociología en Berkeley) combatiendo la idea de que, de alguna manera, el privilegio de la etnografia es que tiene acceso directo a los hechos y es eso lo que le da su "poder". Siempre he dicho que no hay hechos en sí mismos. Si me siento ahora a describir esta habitación durante esta entrevista, podría hacerlo durante el resto de mi vida. Solo cuan- 
do tengo algún tipo de enfoque, algún tipo de conjunto de preguntas, alguna lente, puedo comenzar a hacer ese trabajo en un tiempo finito. Así que no podemos evitar llevar algún tipo de lente al mundo empírico que estudiamos y, de hecho, si no tenemos una lente, el mundo mismo se vería borroso. Eso es lo que sucede en la realidad: todos llevamos implícita o explícitamente un cuerpo teórico que nos ayuda a dar sentido al mundo que nos rodea. Ese es mi punto de partida sobre la relación entre la teoría y el campo: aceptar que la teoría es la esencia de la comprensión de lo que está sucediendo. Por eso, siempre discutí contra aquellos que dicen que tenés que despojarte de toda teoría para poder ver el mundo cuando vas al campo. Es un proyecto que es imposible, pero no solo es imposible, sino que está mal dirigido en mi opinión. La idea es la contraria: reconocer lo que está en tu cabeza en lugar de eliminarlo. Entonces, si ese es el punto de partida, lo que tenemos que hacer cuando hacemos trabajo de campo es construir la teoria y trabajar sobre los hombros de los demás, eso es lo que yo llamo reconstruir la teoria. Porque ¿qué es teoria? La teoria es el conocimiento acumulado entre los académicos (y no académicos también) que, en cierto modo, reconocemos como emergente, como sobresaliente y que, implícitamente, llama nuestra atención sobre el hecho de que somos una comunidad de académicos que trabajan juntos para construir ese conocimiento. Entonces, lo que tenemos que hacer es trabajar con eso y avanzar sobre esa base, en lugar de ir al campo para empezar todo de nuevo y reinventar la rueda. Es decir, la idea es realmente trabajar con lo que existe, esa es la idea de reconstruir la teoría. Esa idea tiene, en la historia de la ciencia y en la filosofia de la ciencia, una larga tradición asociada, en primer lugar, supongo que con Kuhn, pero la persona que a mí me influyó más fue Imre Lakatos y su teoría del Programa de Investigación. Esta no es, necesariamente, la forma más aceptada de pensar acerca de la ciencia, pero creo que es el camino correcto. En este departamento existe, ahora, la opinión de que se puede hacer una etnografia que no sea solo inductiva, es decir que se puede traer la historia a la etnografia si se tiene un cuerpo teórico que te ayude a hacer eso. Pero cuando llegué, hace 40 años, todos pensaron: ¿cómo puede ser marxista? Los etnógrafos no pueden ser marxistas porque los marxistas hacen un trabajo de tipo histórico y los etnógrafos trabajan con lo "micro". Creo que nadie me diría eso hoy.

Hablando de Lakatos, vos tenés un texto muy particular en el que realizás una comparación entre Theda Skocpol y León Trotsky ${ }^{5}$ en relación

5. "Dos métodos en pos de la ciencia: Skocpol vs. Trotsky" en Zona Abierta, 80/81, 1997. 
al modo en que cada uno concibe la acumulación teórica (Skocpol como ejemplo del inductivismo y Trotsky como un ejemplo posible del Programa de Investigación de Lakatos). Cuando lo leí me pareció bastante raro porque nadie trabaja sobre Trotsky en la academia, $y$ si lo hacen, no es para pensar su dimensión epistemológica sino más bien su teoría politica. ¿Por qué tomaste a Trotsky y su teoría de la Revolución Permanente para desarrollar la idea de cómo se reconstruye un cuerpo teórico?

Bueno, el texto es más sobre Skocpol que sobre Trotsky. Skocpol se convirtió en una figura conocida en la sociologia política en los $80 \mathrm{y}$, de hecho, había adoptado una suerte de manto marxista. Ella había sido estudiante de Barrington Moore, que era una figura muy reconocida a partir de su libro Social Origins of Dictatorship and Democracy: Lord and Peasant in the Making of the Modern World, publicado en 1966. Ese libro fue un avance importante en los estudios politicos, nadie había hecho algo a esa escala antes, colocando a los Estados Unidos en un contexto histórico-geográfico mucho más amplio, comparando diferentes caminos hacia la modernidad, comparando la historia de nueve estados. Él, a su vez, era un experto en la Unión Soviética. La Unión Soviética era lo que Barrington Moore tenía efectivamente en la cabeza al hacer ese libro, porque lo que él quería mostrar en realidad era que toda la hostilidad hacia la Unión Soviética, la hostilidad de la Guerra Fría, que se sostenía en el argumento de que era un régimen totalitario, suponía no comprender en qué contexto histórico estaba la Unión Soviética. El trataba de mostrar que, efectivamente, había violencia en la Unión Soviética, pero que esta violencia correspondía al momento de creación del Estado, y que también había habido violencia en la creación del camino hacia la democracia. Eso es lo que él tenía en mente. De modo que está librando una batalla política, no justificando el totalitarismo de la URSS, sino siendo mucho más crítico con Occidente y con la sociología politica que en ese momento estaba celebrando las maravillas de los Estados Unidos. Por ejemplo, personas como Seymour Martin Lipset y su libro El hombre politico (Tecnos, 1987) son argumentos sobre las maravillas de la América liberal. Por supuesto, todo esto hay que entenderlo en el contexto de los años 60. Entonces, Barrington Moore se convirtió en una figura importante y Skocpol era estudiante de Barrington Moore. Así que yo esperaba que ella fuera una especie de marxista. Pero cuando mirás más detenidamente sus escritos, que son básicamente una historia del Estado (el Estado era el centro de muchos debates en ese momento), ella se identificó con la visión de que el Estado debería ser visto como una plataforma autónoma, y estudiarse como tal. Y, en ese sentido, se convirtió en una crítica del marxismo. Así que yo sentí que tenía que tomar su teoría y trabajar sobre ella, ¿qué mejor persona que Trotsky para eso? Porque resulta que Skocpol tenía una teoria muy 
inductiva sobre las revoluciones: hay revoluciones exitosas y fallidas, las exitosas son la rusa, la china y la francesa, y las que no tuvieron éxito son la alemana, la japonesa y lainglesa. Sobre esa información ella hace este tipo de regresión múltiple en la historia para tratar de ver cuáles son las condiciones para un proceso exitoso. Trotsky también intenta comprender por qué la revolución francesa tiene éxito, porqué la alemana no, y porqué la rusa tiene una especie de éxito. Pero el punto de vista central de Trotsky es que estos procesos no pueden verse de forma independiente sino que, por el contrario, todos son parte de un sistema capitalista global en evolución. Skocpol no analiza eso en absoluto. Por eso me pareció muy interesante la comparación entre los dos. Obviamente, desde mi punto de vista, no creo que ella haya estado de acuerdo. De hecho, no sé si leyó realmente mucho de Trotsky, no hay mucha evidencia de que lo haya leído. Así que usé esa comparación para pensar en el significado de la ciencia, la ciencia del sociólogo, y el significado de la teoría. Skocpol representaba este enfoque inductivo que yo había criticado también en el contexto de la etnografia. Su trabajo histórico comparativo, que era realmente importante, obviaba las conexiones entre estas revoluciones y el contexto general en el que ellas se desarrollaban. Al contrario, Trotsky había sido increíblemente sensible a eso, la teoría de la revolución permanente y el concepto de desarrollo desigual y combinado eran una muestra de esa sensibilidad y eran, a mi juicio, una muestra de la reconstrucción de la teoria marxista. Y lo interesante de Trotsky es que su Historia de la Revolución Rusa ${ }^{6}$ es una etnografia en la que él entiende de una manera que muy pocos lo hacen este vínculo entre la experiencia vivida y las macro fuerzas más amplias que están en funcionamiento. Así que puse su elaboración en el contexto del desarrollo del marxismo, destacando que Trotsky fue un jugador muy importante en eso, cosa que no era necesariamente una opinión común.

¿Y cómo ves la reconstrucción de la teoría marxista en la actualidad? Vos solés hablar, por un lado, de la crisis que está atravesando la universidad como institución; y por otro, de la oportunidad que existe hoy para la reconstrucción de la sociología como ciencia, asociada a la idea de una sociología pública; pero diferencias tu noción de sociología pública de la que tiene, por ejemplo, Pierre Bourdieu...

Esta cosa de sociología pública es otra cosa extraña. Aparece cuando volví a Sudáfrica en 1991, y encontré una sociología que en Argentina quizás sea normal y natural, pero que no lo es en los Estados Unidos, era una sociología con gente comprometida. Quiero decir que los

6. Historia de la Revolución Rusa, Buenos Aires: IPS-CEIP, 2017. 
sociólogos, no todos ellos, pero muchos de ellos, estaban en realidad comprometidos en la batalla contra el régimen del apartheid y bajo ese compromiso llevaban adelante su tarea de sociólogos. Al mismo tiempo que enseñaban, se involucraban politicamente y trataban de desarrollar una sociología bastante regional. Habiendo pasado tantos años en los Estados Unidos nunca había visto una sociología de este tipo y me había acostumbrado a la sociología de tipo muy profesional en la que los sociólogos escriben cosas, incluso escriben cosas sobre Skocpol y Trotsky y, en el mejor de los casos, lo leen una o dos personas más. De hecho, nadie por fuera de la academia lee lo que se produce en la academia y eso es tomado como normal. Ese es un modelo de sociología profesional basada en el intercambio de documentos entre los que pertenecemos a ella. Recuerdo que cuando (Fernando Henrique) Cardoso estuvo aquí en 1980 o 1981, siempre se reía de la forma en que opera la sociologia estadounidense o los académicos estadounidenses: "Hacen todas estas valientes afirmaciones revolucionarias, pero, ya sabes, nadie lo lee, así que no importa". Pero de donde él venía, Brasil en el periodo de la dictadura, si comenzabas a hacer declaraciones revolucionarias podías tener problemas. Así que, cuando en 1994 me convertí en jefe de este Departamento de Sociología, decidimos que la nuestra iba a ser una sociología pública porque este Departamento, a diferencia de todos los otros en los Estados Unidos, tenía a los sociólogos más comprometidos, comprometidos con el mundo más allá de la academia. Así fue que decidimos impulsar esta idea de hablar de "sociología pública". Mis colegas lo han lamentado desde entonces, pero sin embargo, eso es lo que sucedió. La idea era contrastar la sociología pública con la sociología profesional, y la inspiración proviene originalmente de Sudáfrica. Pero después pensé "bueno, tal vez haya diferentes tipos de sociología pública". Así que tomé la distinción de Gramsci, aunque en realidad nunca me referí a Gramci explícitamente, para aplicarla a la distinción entre una "sociología pública tradicional" y una "sociología pública orgánica", y creo que lo que la mayoria de la gente estaba haciendo aquí en el Departamento era una sociedad pública tradicional. Comunicaban sus ideas a través de los medios, a través de los libros que escribían para un público más amplio más allá de la academia. Pero también podía haber una sociología pública orgánica que tiene una relación no mediada entre el sociólogo o el académico y la comunidad. Y, por supuesto, ese tipo de relación es la que Gramsci también enfatizó, solo que él lo hace a nivel colectivo, no a nivel individual. El intelectual orgánico de Gramsci es quien puede elaborar lo que él llamó el "buen sentido" de la clase trabajadora. Un núcleo duro de su teoría es que la clase trabajadora, en virtud de su transformación colectiva, puede entender el mundo; las clases subordinadas pueden entender el mundo. 
Es decir, el "buen sentido" es posible, hay infiltración de la ideología burguesa, pero existe también la posibilidad del "buen sentido". Entonces, hay algo que los intelectuales deben hacer: está ese buen sentido con el que tienen que trabajar. En Bourdieu no existe el "buen sentido", solo existe el "mal sentido". La clase trabajadora no puede entender las condiciones de su propio sometimiento. Por lo tanto, en cierto sentido, los intelectuales deben ellos mismos transformar el mundo. Ellos son, como yo lo entiendo, los que pueden tener una presencia progresiva. Pero no todos los intelectuales. Muchos de los intelectuales sufren lo que los marxistas llamarian una falsa conciencia, han sido objeto de falacias escolásticas, motivo por el cual solo unos pocos sociólogos realmente pueden entender el mundo, particularmente los que están cerca de Bourdieu, quizás solo el propio Bourdieu. Pero de cualquier modo, esta idea de que el intelectual es el agente transformador (y no los dominados) me hace pensar que Gramsci vería a Bourdieu como un intelectual tradicional, crítico del mundo circundante, pero cuya crítica en sí misma no desafia la totalidad. De hecho, el intelectual tradicional, en virtud de ser crítico, parece ser autónomo y parece que puede presentarse como portavoz de esa autonomía, de esa universalidad; mientras que el intelectual orgánico está estrechamente relacionado con algún tipo de clase que será el agente de transformación, una clase subordinada que será transformadora. Gramsci consideraría a Bourdieu como un intelectual tradicional y a sí mismo como un intelectual orgánico. Bourdieu, por otro lado, vería a Gramsci como un creyente engañado por el mito del intelectual orgánico, y equivocado al pensar que la clase trabajadora tiene este papel emancipador. Empíricamente no está del todo claro quién tiene razón, pero políticamente uno tiene sus propias propensiones. De cualquier modo creo que hay mucho más en juego, que es la pregunta acerca de dónde viene la verdad: para Gramsci, la verdad proviene de la experiencia de la clase trabajadora, ya que transforma la naturaleza. Para Bourdieu, la verdad en última instancia proviene del ámbito educativo, de la existencia de intelectuales que participan en un campo de competencia y producen la verdad. Entonces tienen una visión diferente de la verdad y eso tiene enormes implicaciones políticas.

Relacionado con esta idea de intelectual orgánico, me gustaria saber cómo pensas hoy la relación entre el marxismo y sus implicancias politicas. Vos hacés una suerte de periodización del marxismo en los últimos 150 años: el marxismo clásico, el ruso, el occidental, el tercermundista y al llegar a la actualidad, afirmás que este es el momento del "marxismo sociológico". Pero yo no llego a entender qué es el "marxismo sociológico" porque los otros marxismos a los que hacés referencia están relacionados a distintos momentos de ascenso de la lucha de clases lo de derrota, 
como dice Perry Anderson sobre el marxismo occidental). Entonces, ¿con qué movimiento orgánico, con qué movimiento de clase trabajadora está relacionado este marxismo sociológico? ¿La idea de marxismo sociológico no es una contradicción en los términos?

Sí, es muy contradictorio lo que estoy diciendo. Eso es absolutamente cierto. ¿Este marxismo sociológico está de alguna manera orgánicamente conectado? ¿Qué significaria eso? Esto es lo que yo diría: significa traer de vuelta lo social al centro de la escena. El marxismo, en primer lugar, había enfatizado la economía. De alguna manera, la economía sembraría las semillas de su propia destrucción. La segunda posición fue una visión del socialismo que puso en el centro al Estado. Entonces, lo que falta es un marxismo que centre lo social. Por supuesto que para pensar esto recurro a Polanyi y a Gramsci para enfatizar la importancia de una visión del socialismo basada en la autoorganización colectiva de la sociedad civil, eso es el marxismo sociológico.

\section{¿Dónde ponés a Trotsky en este esquema?}

Tenemos que ser cuidadosos, lo pondría básicamente en el socialismo centrado en el Estado. Es complicado porque no es que él fuera parte del marxismo soviético, pero creo que la visión del socialismo que tiene Trotsky es la de un socialismo dirigido por el Estado, la clase trabajadora es importante y, además, Trotsky cambia de opinión con el tiempo, pero aún así creo que su contribución es el reconocimiento de la centralidad del Estado y no un análisis elaborado de la forma en que la sociedad civil configura a las clases. Por supuesto que después de la revolución [rusa] el problema central era cómo entender básicamente la construcción de la hegemonía desde arriba. Entonces, su análisis de Rusia post revolución, su crítica a Stalin, sus propuestas del Programa de transición, tienen todos en el centro al Estado. Creo, además, que eso también está implícito en sus escritos anteriores, porque Trotsky no es alguien que cree de algún modo que la economía sembrará las semillas de su propia destrucción. Se podría argumentar que tiene algún tipo de análisis de la sociedad civil, pero creo que es un análisis muy flaco. Gramsci sí lo plantea como la característica central del capitalismo avanzado. No creo que Trostky considere que la sociedad civil es tan crucial como para exigir una visión completamente diferente de la revolución como Gramsci dice que es necesaria. De cualquier modo, el marxismo sociológico implica poner en el centro lo social y la llamada sociedad civil y su reorganización colectiva. Pero lo que señalás es un buen punto, porque el marxismo sociológico es más bien un proyecto académico y los otros marxismos, o muchos de ellos, se desarrollaron en estrecho contacto con una clase trabajadora movilizada. De allí que hablar de marxismo sociológico puede ser una contradicción en los términos en el sentido 
de que el marxismo tiene que estar, de alguna manera, desarrollado en estrecha conexión con los dominados. Pero diria que lo que mi amigo Eric Olin Wright plantea como sus ideas sobre las "utopías reales" es, en cierto sentido, una expresión del marxismo sociológico: desarrollarse en estrecha conexión con aquellos que se dedican a construir instituciones alternativas para desafiar al capitalismo, ya sea que estemos hablando de presupuestos participativos o de cooperativas, tienen el potencial de desafiar al capitalismo, y uno puede conocerlos y ser portavoz de sus ideas a través de relacionarse realmente con aquellos que están intentando construir estas instituciones alternativas. Si tomamos en serio sus proyectos ponemos en contacto el marxismo sociológico con quienes están construyendo instituciones alternativas al capitalismo. Esa es mi defensa, supongo. 